\title{
Article \\ Comparing Operational, Environmental and Eco-Efficiency of Water Companies in England and Wales
}

\author{
Ramón Sala-Garrido ${ }^{1}\left(\mathbb{D}\right.$, Manuel Mocholí-Arce ${ }^{1}{ }^{(\mathbb{C}}$, María Molinos-Senante ${ }^{2, *}$ and Alexandros Maziotis ${ }^{2}$ \\ 1 Departamento de Matemáticas para la Economía y la Empresa, Universidad de Valencia, \\ 46071 Valencia, Spain; sala@uv.es (R.S.-G.); Manuel.mocholi@uv.es (M.M.-A.) \\ 2 Departamento de Ingeniería Hidráulica y Ambiental, Pontificia Universidad Católica de Chile, \\ Santiago 4860, Chile; alexandros.maziotis@gmail.com \\ * Correspondence: mmolinos@uc.cl; Tel.: +56-971934218
}

Citation: Sala-Garrido, R.;

Mocholí-Arce, M.; Molinos-Senante,

M.; Maziotis, A. Comparing

Operational, Environmental and

Eco-Efficiency of Water Companies in England and Wales. Energies 2021, 14, 3635. https://doi.org/10.3390/ en14123635

Academic Editor: Sanghyun Jeong

Received: 18 May 2021

Accepted: 15 June 2021

Published: 18 June 2021

Publisher's Note: MDPI stays neutral with regard to jurisdictional claims in published maps and institutional affiliations.

Copyright: (c) 2021 by the authors. Licensee MDPI, Basel, Switzerland. This article is an open access article distributed under the terms and conditions of the Creative Commons Attribution (CC BY) license (https:// creativecommons.org/licenses/by/ $4.0 /)$.

\begin{abstract}
The assessment of performance of water companies is essential for their regulation. In doing so, several variables and models can be employed. This study evaluates and compares the performance of a sample of English and Welsh water companies from the operational, environmental and eco-efficiency perspectives by applying the non-radial data envelopment analysis range adjusted measure model. This methodological approach allows integrating greenhouse gas emissions as undesirable output. The results indicated that the water industry performed well from an operational perspective. However, environmental inefficiency considerably exists which illustrates the difficulties of the water companies in reducing greenhouse gas emissions. The average eco-efficiency was 0.783 which means that while expanding water services, water companies could further reduce costs and carbon emissions by $11.7 \%$ on average. Other factors such as water treatment complexity and population density significantly affect water companies' eco-efficiency. Several policy implications are finally discussed.
\end{abstract}

Keywords: eco-efficiency; greenhouse gas emissions; non-radial DEA; water treatment and supply; water utilities; sustainability

\section{Introduction}

Water companies are obliged to deliver drinking water according to quality standards defined by the water regulator and safely discharge treated wastewater to the environment using minimum economic costs [1]. The supply of water and wastewater services releases greenhouse gas emissions (GHG) to the atmosphere which are mainly because of energy use in all parts of the supply chain [2,3]. Over the years, researchers and policy makers have been making efforts to understand the water-energy-GHG nexus because it impacts climate change [4]. For instance, Lam et al. [5], Lee et al. [6] and Wang et al. [7] concluded that the energy requirements in water and wastewater production process could potentially increase due to population growth and climate change. Thus, the need to invest in new technologies that could reduce the carbon emissions during the water and wastewater production process is of outmost importance for sustainable development [8]. Policy makers in several countries around the world set targets in reducing GHG emissions in all sectors in economy including the water sector. For instance, the state of Victoria in Australia is committed to reduce GHG to zero by 2050 [9]. The United Kingdom Government is also committed that the water sector should cut down its GHG emissions by $80 \%$ by 2050 [10].

Traditionally the measurement of performance of water production process was conducted including inputs (e.g., operational costs) and desirable outputs (e.g., volumes of water delivered) employed by water utilities. In other words, it has been evaluated the efficiency of water utilities in the provision of drinking water [11-13]. More recently, several undesirable outputs such as water leakage were included in the analysis based on the approach developed by Chung et al. [14] and Fare and Grosskopf [15]. Recent studies 
by Ananda and Kampf [4], Ananda [8,16] included in their analysis, as undesirable outputs, GHG emissions from the operation of water and sewerage facilities. This assessment allows estimating jointly the economic and environmental performance of water utilities, i.e., its eco-efficiency.

According to the literature review conducted by Goh and See [13], the eco-efficiency assessment of water utilities has been done by using production frontiers that could be estimated using parametric (econometric) and non-parametric (linear programming (LP)) techniques. The most widely used non-parametric technique is the Data Envelopment Analysis (DEA) $[16,17]$ which compares the performance of each unit (water utility) relative to the best industry's frontier [18]. Unlike parametric techniques, DEA does not presume a priori a functional form for the technology [19] so this technique is used in this study.

There are two main groups of DEA models; the radial and non-radial models [20]. Charnes et al. [18] and Banker et al. [21] developed the radial DEA models. In these models, the technical efficiency (and also eco-efficiency) is estimated as a score in the objective function of the LP model [22]. However, these models assume a proportional contraction of all inputs while output remains fixed. Consequently, this is a relevant limitation of radial DEA models $[23,24]$. On the other hand, the non-radial DEA models estimated the technical efficiency using slacks [22]. This permits estimating the efficiency of each input or each output [23]. There are several examples of non-radial DEA models such as the additive model established by Charnes et al. [24], the slack-based model introduced by Tone [25], the "range-adjusted measure" (RAM) advanced by Cooper et al. [26-30], the enhanced Russel graph measure of efficiency [31]. While each non-radial DEA model has pros and cons, the RAM-DEA model can easily integrate operational and environmental efficiency for each water utility in a united manner [32-37]. Thus, the RAM-DEA model is used in our study to evaluate the eco-efficiency of water supply process. Given the positive features of the RAM-DEA model, there have been several studies that calculated the eco-efficiency of companies in the energy sector (for a review see Sueyoshi et al. [27]). However, to the best of authors' knowledge there have not been any studies in the water industry evaluating its eco-efficiency by employing the RAM-DEA approach.

Consequently, the core objective of this study is to evaluate and compare the operational efficiency (OE), environmental efficiency (EE), and eco-efficiency (ECOE) of several water utilities using RAM-DEA models. In doing so, we employed three non-radial DEA models. The first one estimates OE by expanding desirable outputs (i.e., drinking water delivered and water connected properties) and contracting inputs (i.e., operational costs). The second model estimates EE by contracting inputs and undesirable outputs (i.e., GHG emissions). The third non-radial DEA model integrates both operational and environmental efficiency in a unified framework $[38,39]$, i.e., it estimates the ECOE of water utilities. This is a novel approach, as to the best of authors' knowledge, this is the first study that assessed the eco-efficiency of water production process using non-radial RAM-DEA techniques. As we want to get a better insight on what drives companies' efficiency, we further regress the eco-efficiency scores against a set of environmental factors. The empirical approach deals with the drinking water services provided by several water and sewerage companies (WaSCs) and water only companies (WoCs) in England and Wales during the years 2011-2018. We also relate the findings to the regulatory cycle to discuss the effect of regulation on companies' eco-efficiency. The paper concludes with the discussion of several policy implications.

\section{Materials and Methods}

\subsection{Estimation of Operational Efficiency, Environmental Efficiency and Eco-Efficiency}

This section describes the methodology employed to assess the OE, EE, and ECOE of several water utilities (companies) in England and Wales using RAM-DEA models. We suppose that $k$ water utilities exist and the $j$ th company $(j=1, \ldots, k)$ use a vector of $m$ inputs $X_{j}=\left(x_{j 1}, \ldots, x_{j m}\right)$ to generate a set of $s$ desirable outputs $Y_{j}=\left(y_{j 1}, \ldots, y_{j s}\right)$ and 
$r$ undesirable outputs $B_{j}=\left(b_{j 1}, \ldots, b_{j r}\right)$. The $\mathrm{OE}$ of the particular $n$th water company can be evaluated using the following RAM-DEA model:

$$
\begin{gathered}
\max \frac{\left(\sum_{i=1}^{m} \frac{d_{i}^{x}}{R_{i}^{x}}+\sum_{q=1}^{s} \frac{d_{q}^{y}}{R_{q}^{y}}\right)}{(m+r)} \\
\text { s.t. } \\
\sum_{i=1}^{k} x_{i j} \lambda_{i j}+d_{i}^{x}=x_{i n} \quad(i=1, \ldots, m) \\
\sum_{j=1}^{k} y_{q j}-d_{q}^{y}=y_{q n} \quad(q=1, \ldots, s) \\
\sum_{j=1}^{k} \lambda_{j}=1, \quad \lambda_{j} \geq 0 \quad(j=1, \ldots, k) \\
d_{i}^{x} \geq 0 \quad(i=1, \ldots, m) \\
d_{q}^{y} \geq 0 \quad(q=1, \ldots, s)
\end{gathered}
$$

where $\lambda$ denotes intensity variables employed to create the production frontier, $d_{i}^{x}$ and $d_{q}^{y}$ are slack variables for inputs and desirable outputs, respectively. The ranges of inputs and desirable outputs are given by their upper and lower bounds as follows [36]:

$$
\begin{gathered}
\overline{x_{i}}=\max \left\{x_{i j}\right\} \text { and } \overline{y_{q}}=\max \left\{y_{q j}\right\}: \text { upper bounds } \\
\underline{x_{i}}=\min \left\{x_{i j}\right\} \text { and } \underline{y_{q}}=\min \left\{y_{q j}\right\}: \text { lower bounds }
\end{gathered}
$$

Then the ranges, $R_{i}^{x}$ and $R_{q}^{y}$ in Model (1) are defined as follows:

$$
R_{i}^{x}=\overline{x_{i}}-\underline{x_{i}} \text { and } R_{q}^{y}=\overline{y_{q}}-\underline{y_{q}}
$$

Thus, the efficiency score $\varphi$ for OE can be derived as follows:

$$
\varphi=1-\frac{\left(\sum_{i=1}^{m} \frac{d_{i}^{x *}}{R_{i}^{x}}+\sum_{q=1}^{s} \frac{d_{q}^{y *}}{R_{q}^{y}}\right)}{(m+s)}
$$

where the subscript $\left(^{*}\right)$ denotes the optimality of Model (1) [40].

The EE of particular $n$th water company can be evaluated using the following RAMDEA model:

$$
\begin{gathered}
\max \frac{\left(\sum_{i=1}^{m} \frac{d_{i}^{x}}{R_{i}^{x}}+\sum_{p=1}^{r} \frac{d_{p}^{b}}{R_{p}^{b}}\right)}{(m+r)} \\
\text { s.t. } \\
\sum_{i=1}^{k} x_{i j} \lambda_{i j}-d_{i}^{x}=x_{i n} \quad(i=1, \ldots, m) \\
\sum_{j=1}^{k} b_{p j}+d_{p}^{b}=b_{p n} \quad(b=1, \ldots, r) \\
\sum_{j=1}^{k} \lambda_{j}=1, \quad \lambda_{j} \geq 0 \quad(j=1, \ldots, k) \\
d_{i}^{x} \geq 0 \quad(i=1, \ldots, m) \\
d_{p}^{b} \geq 0 \quad(p=1, \ldots, r)
\end{gathered}
$$

where $d_{p}^{b}$ is the slack variable for undesirable outputs. Then the range, $R_{p}^{b}$ in Model (5) is defined as follows:

$$
R_{p}^{b}=\overline{b_{p}}-\underline{b_{p}} \text { where } \overline{b_{p}}=\max \left\{b_{p j}\right\} \text { and } \underline{b_{p}}=\min \left\{b_{p j}\right\}
$$

Thus, the efficiency score $\theta$ for EE can be derived as follows:

$$
\theta=1-\frac{\left(\sum_{i=1}^{m} \frac{d_{i}^{x *}}{R_{i}^{x}}+\sum_{p=1}^{r} \frac{d_{p}^{b *}}{R_{p}^{b}}\right)}{(m+r)}
$$


The unified operational and environmental performance, i.e., ECOE, of the particular $n$th water company can be assessed using the following RAM-DEA model:

$$
\begin{aligned}
& \max \frac{\left(\sum_{i=1}^{m} \frac{\left(d_{i}^{x+}+d_{i}^{x-}\right)}{R_{i}^{x}}+\sum_{q=1}^{s} \frac{d_{q}^{y}}{R_{q}^{y}}+\sum_{p=1}^{r} \frac{d_{p}^{b}}{R_{p}^{b}}\right)}{(m+s+r)} \\
& \text { s.t. } \\
& \sum_{i=1}^{k} x_{i j} \lambda_{i j}-d_{i}^{x+}+d_{i}^{x-}=x_{i n} \quad(i=1, \ldots, m) \\
& \sum_{j=1}^{k} y_{q j}-d_{q}^{y}=y_{q n} \quad(q=1, \ldots, s) \\
& \sum_{j=1}^{k} b_{p j}+d_{p}^{b}=b_{p n} \quad(p=1, \ldots, r) \\
& \sum_{j=1}^{k} \lambda_{j}=1, \quad \lambda_{j} \geq 0 \quad(j=1, \ldots, k) \\
& d_{i}^{x+} \geq 0 \quad(i=1, \ldots, m) \\
& d_{i}^{x-} \geq 0 \quad(i=1, \ldots, m) \\
& d_{q}^{y} \geq 0 \quad(q=1, \ldots, s) \\
& d_{p}^{b} \geq 0 \quad(p=1, \ldots, r)
\end{aligned}
$$

In this model, the slack variable associated with input is split into its negative and positive parts [36]. The efficiency score $\sigma$ for ECOE is defined as follows:

$$
\sigma=\frac{\left(\sum_{i=1}^{m} \frac{\left(d_{i}^{x+*}+d_{i}^{x-*}\right)}{R_{i}^{x}}+\sum_{q=1}^{\mathcal{S}} \frac{d_{q}^{y *}}{R_{q}^{y}}+\sum_{p=1}^{r} \frac{d_{p}^{b *}}{R_{p}^{b}}\right)}{(m+s+r)}
$$

\subsection{Influence of Environmental Variables on Eco-Efficiency Scores}

In this section we describe the approach we used to get a better insight of what might drive the eco-efficiency of water companies. We regressed the eco-efficiency scores against a set of explanatory factors that were associated with topography, treatment complexity and density $[10,41]$. As the eco-efficiency scores are truncated between 0 and 1 , we used Tobit regression to obtain reliable results [10,41-49]. The Tobit model was defined as follows:

$$
\varphi_{j, t}=a_{0}+a_{j} z_{j, t}^{\prime}+\eta_{j}+\varepsilon_{j, t}
$$

where $\varphi_{j, t}$ denotes the eco-efficiency of each water company $j$ at any period $t, a_{0}$ is the intercept (constant) term, $z_{j t}^{\prime}$ is the vector of environmental variables of any water company $j$ at any time. Moreover, in the above regression model, $\eta_{j}$ captures water company's unobserved heterogeneity (e.g., managerial ability) which is uncorrelated with the environmental variables and is distributed following the standard normal distribution, and $\varepsilon_{l, t}$ is the error (noise) term that is normally distributed [10,41].

\section{Case Study Description}

The empirical application evaluates the OE, EE and ECOE of 10 WaSCs and 7 WoCs in UK during the 2011-2018 period. The economic regulator, the Water Services Regulation Authority (Ofwat), monitors the performance of water companies. Every five years it sets the revenues that the water companies are allowed to recover from customers by challenging and approving companies' business plans (price determinations) [50]. The data used in this study comes from Ofwat and companies' websites.

Following previous published evidence in the water sector (e.g., [13,51-53] we chose the following inputs, desirable outputs and undesirable outputs. Two inputs were selected: (i) the water energy expenditure (costs) measured in millions of £ every year $[10,41,54]$, and (ii) the other water expenditure (costs) [50]. This was calculated as the difference between water operating cost and water energy cost $[10,41]$. Other costs were measured in millions of $£$ per year $[10,41]$. The desirable outputs were defined as follows. We used the annual volume of drinking water delivered measured in megalitres [55-58]. The 
second desirable output was defined as the annual number of water connected properties measured in thousands $[59,60]$. The undesirable output was presented by the GHG emissions from the process of water services [4,10,61-64]. They were expressed in tons of $\mathrm{CO}_{2 \text { eq }}$ per year and are measured following the UK Government Environmental Reporting Guidelines [10,41,65].

Moreover, several studies in the past e.g., [51-53] stated that there might be several environmental factors that could impact on companies' performance. Consequently, we selected the following variables which were based on topography, water treatment complexity and density [41,66-68]. The variables used to capture topography included: (i) the water taken from boreholes measured in percentage [10,60,69]; (ii) the water taken from rivers measured in percentage $[10,41,70]$, (iii) average pumping head as a proxy for the energy requirements to supply water to end-users $[10,41,60]$. We included two variables to capture treatment complexity: (iv) the water that gets advanced treatment measured in percentage (for more details please see [66-68,71] and (v) the number of treatment works required to treat water that comes from surface $[41,71,72]$. Finally, we included population density which was calculated as a ratio of water population and area [69-73]. Table 1 summarizes the descriptive statistics for the variables employed in the empirical application.

Table 1. Descriptive statistics.

\begin{tabular}{|c|c|c|c|c|c|}
\hline Variables & Unit of Measurement & Mean & Std. Dev. & Minimum & Maximum \\
\hline Water delivered & $\mathrm{Ml} /$ year & 717 & 554 & 56 & 2169 \\
\hline Water connected properties & $000 \mathrm{~s} /$ year & 1490 & 1118 & 123 & 3826 \\
\hline Greenhouse gas emissions & tonCO $\mathrm{C}_{2 \mathrm{eq}} /$ year & 86,151 & 70,335 & 4542 & 275,900 \\
\hline Energy costs & $£ \mathrm{~m} /$ year & 19.72 & 14.58 & 1.51 & 59.99 \\
\hline Other costs & $£ \mathrm{~m} /$ year & 91.17 & 75.85 & 7.56 & 331.65 \\
\hline Water taken from rivers & $\%$ & 27.8 & 24.8 & 0.0 & 85.7 \\
\hline Water taken from boreholes & $\%$ & 41.0 & 31.5 & 0.5 & 100.0 \\
\hline Surface water treatment works & $\mathrm{nr}$ & 15.043 & 15.075 & 1.000 & 54.000 \\
\hline Water receiving advanced treatment & $\%$ & 93.0 & 5.4 & 81.0 & 100.0 \\
\hline Average pumping head & $\mathrm{nr}$ & 138.911 & 36.937 & 64.820 & 224.210 \\
\hline Population density & $000 \mathrm{~s} / \mathrm{km}^{2}$ & 0.462 & 0.275 & 0.146 & 1.250 \\
\hline
\end{tabular}

\section{Results and Discussion}

\subsection{Assessment of Operational Efficiency, Environmental Efficiency and Eco-Efficiency}

Figure 1 reports the average estimates of the OE, EE and ECOE of the English and Welsh water industry during the years 2011-2018. The results indicated that, on average, water companies performed excellent from an operational perspective (i.e., by considering inputs and desirable outputs as variables) as the mean efficiency score was 0.972 . This means that the UK water sector could further decrease its energy and other costs by $2.8 \%$ while expanding its water services by the same level to improve performance. However, this measure does not include the undesirable outputs. When carbon emissions are incorporated in the performance estimation, water companies reported lower efficiency scores from an environmental point of view. It is found that the potential savings for inputs and carbon emissions among water companies was approximately $14.6 \%$ on average. The combination of operational and environmental performance leads to the measurement of eco-efficiency. It is found that during the years 2011-2018 the mean ECOE was 0.783 which means that costs and carbon emissions could further reduce by $11.7 \%$ on average.

We next discuss the trend in the efficiency scores. OE followed a decreasing trend during the years $2011-2015$ at a rate of $0.31 \%$ per year. This means that increases in energy and other costs had a negative impact on companies' OE. The situation changed the forthcoming years where the water industry appeared to have made gains in its efficiency. Compared to 2011, OE improved from 0.976 to 0.984 in 2018, an improvement by $0.82 \%$. Dealing with carbon emissions was challenging for the industry. There was an increasing trend in EE during the years 2011-2015. EE was progressing at an annual rate of $0.16 \%$ 
meaning that water companies were able to reduce costs and carbon emissions during that period. We also note that in 2011 the mean EE was already at high levels, 0.893 and small efficiency gains were achieved till 2015. However, a decreasing trend was apparent the following years which was attributed to increases in carbon emissions and production costs. It is noted that energy and other costs increased by $5 \%$ and $6 \%$, respectively, which led to higher increases in overall costs. As a result, the use of more energy and other costs in the production costs might have a negative impact on carbon emissions which showed an increase of $10 \%$ compared to previous year. Overall, EE considerably reduced which means that the water companies needed to make more efforts to invest in new carbon technologies that could reduce GHG emissions. As for the trend in the ECOE scores, it appears that it was mainly driven from the EE. It follows an increasing trend during the years $2011-2015$ as ECOE was increasing at a small rate of $0.42 \%$ per year on average. In the forthcoming years, it followed a decreasing trend due to an increase in the level of carbon emissions. Overall, the results indicated that eco-inefficiency in the English and Welsh water industry exists. A decreasing trend in ECOE was evident from 2015 onwards. Water companies should use new carbon efficient technologies to reduce production costs and carbon emissions. Moreover, it is of great importance to incorporate GHG emissions in the analysis to improve business decision making process.

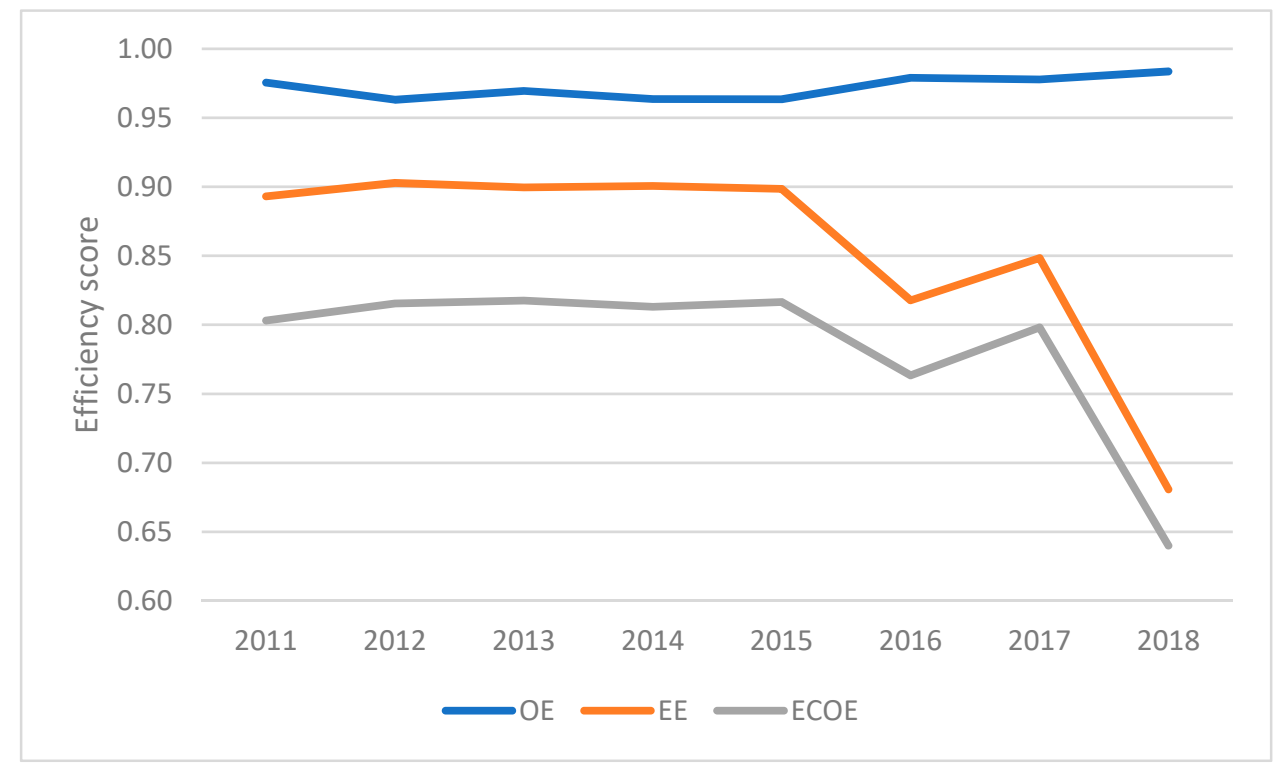

Figure 1. Evolution of average operational efficiency (OE), environmental efficiency (EE) and ecoefficiency (ECOE) of English and Welsh water companies.

Since the sample evaluated in this empirical application consists of both WaSCs and WoCs, we report the efficiency scores by company type (Table 2). We divided the period into two sub-periods, i.e., 2011-2015 and 2016-2018 to relate the findings to the regulatory cycle. The results indicated that WaSCs performed better than WoCs when GHG emissions are included in the estimation. From an operational point of view, there was no difference in the efficiency scores between WaSCs and WoCs. Regardless of company type, there is room for improvement in terms of both OE and EE. In particular, during the years 20112018, the OE of WaSCs and WoCs was 0.972 which means that water companies needed to further reduce their costs and expand their water services by $2.8 \%$ on average. By contrast, lower EE and ECOE scores were reported. The mean EE of WaSCs and WoCs was 0.864 and 0.843 which means that costs and GHG emissions could further reduce by $13.60 \%$ and $15.74 \%$, respectively. The results from the ECOE score indicated that average WaSC should further reduce costs and carbon emissions by almost $20 \%$ when trying to expand its water services. Moreover, the further increase in WoC's volumes of water delivered 
and connected properties required the contraction of energy and other costs, and carbon emissions by almost $25 \%$ on average.

Table 2. Operational efficiency (OE) environmental efficiency (EE) and ecoefficiency (ECOE) for English and Welsh water and sewerage companies (WaSCs) and water only companies (WoCs).

\begin{tabular}{ccccccc}
\hline \multirow{2}{*}{ Year } & \multicolumn{3}{c}{ WaSCs } & & & WoCs \\
\cline { 2 - 7 } & OE & EE & ECOE & OE & EE & ECOE \\
2011 & 0.979 & 0.900 & 0.822 & 0.970 & 0.882 & 0.776 \\
2012 & 0.965 & 0.911 & 0.835 & 0.961 & 0.892 & 0.787 \\
2013 & 0.972 & 0.907 & 0.835 & 0.966 & 0.889 & 0.793 \\
2014 & 0.962 & 0.910 & 0.832 & 0.965 & 0.888 & 0.785 \\
2015 & 0.961 & 0.913 & 0.841 & 0.967 & 0.878 & 0.782 \\
2016 & 0.980 & 0.819 & 0.773 & 0.977 & 0.816 & 0.749 \\
2017 & 0.976 & 0.868 & 0.825 & 0.980 & 0.821 & 0.759 \\
$2011-2015$ & 0.982 & 0.684 & 0.658 & 0.987 & 0.676 & 0.614 \\
Average & 0.968 & 0.908 & 0.833 & 0.966 & 0.886 & 0.785 \\
\end{tabular}

We turn now our discussion in the trend of the efficiency scores for WaSCs and WoCs and the regulatory cycle. During the first sub-period (2011-2015), which is the period covered by the 2009 price determination (price review), Ofwat adopted several schemes to incentivize water companies to improve operational and environmental performance. For instance, water companies were permitted to maintain any savings made in operating expenditure no matter which year they were made [74]. Furthermore, Ofwat introduced the Service Incentive Scheme (SIM), a set of several performance indicators related to quality of service and environment, and provided financial rewards for the companies who performed well [69]. The results indicated that there was an increasing trend in mean water companies' ECOE which takes into account both environmental and operational efficiency. WaSC and WoC's ECOE was increasing at an annual rate of $0.57 \%$ and $0.20 \%$, respectively. In particular, WaSC's mean ECOE increased from 0.822 in 2011 to 0.841 in 2018, an increase of 2.72\%, whereas WoC's mean ECOE improved from 0.776 in 2011 to 0.782 in 2018 , an increase of $0.766 \%$. Although these efficiency scores were among the highest ones achieved during the entire period, it demonstrates that WaSCs and WoCs still need to make considerable reductions in costs and carbon emissions to improve eco-performance. Moreover, during the same sub-period WaSC performed slightly better than WoCs from an operational point of view. However, the decrease in WaSCs' OE was higher than WoCs. In particular, average WaSC's OE was decreasing at an annual rate of $0.46 \%$ whereas the rate of decrease in average $\mathrm{WoC}^{\prime}$ s efficiency was at the level of $0.09 \%$. We note that during the years 2014-2015, WoCs' mean OE was higher than the one reported by WaSCs which means that WoCs managed to make some gains in efficiency. However, OE focused on inputs and desirable outputs and did not include carbon emissions. When the latter is included in the analysis, then WoCs' efficiency is lower than WaSCs. It appears that WaSCs' mean EE was increasing at rate of $1.4 \%$ per year whereas WoCs' mean EE deteriorated. We note that during that period WaSCs reported high levels of EE, whereas WoCs did not perform well in their daily operations, in reducing production costs and carbon emissions.

We next analyze the results from the second sub-period (2016-2018) which is the period covered by the 2014 price review. During that period Ofwat maintained the rolling incentive mechanism adopted in the previous period (savings in operating expenditure) and replaced SIM with a new incentive scheme to monitor service quality and environmental performance. This scheme included a set of common and bespoke performance indicators that water companies needed to report every year. These indicators aimed to provide excellent quality of service at an efficient expenditure and to enhance sustainability of the industry. Examples include water leakage, unplanned interruptions, pollution 
incidents, GHG emissions. Targets were set for each performance indicator that companies needed to achieve during the year or at the end of the regulatory period (Outcome Delivery Incentives-ODIs) [69]. If targets are met (outcomes are delivered), then water companies are rewarded financially (e.g., in case of water leakage) or in terms of reputation (e.g., in case of GHGs). If not, they are penalized. The findings from this study, indicated that the 2014 price review appeared to be challenging for both WaSCs and WoCs. If carbon emissions are ignored, then $\mathrm{OE}$ for both WaSCs and WoCs followed an increasing trend. OE was increasing at an annual rate of $0.71 \%$ and $0.67 \%$, respectively. It also showed that WoCs showed higher levels of OE than WaSCs suggesting that gains in efficiency for WoCs were increasing over time. However, this picture is incomplete as it does not include undesirable outputs in the analysis. Consequently, during the years 2016-2018 the ECOE for WaSCs and WoCs was volatile and was mainly driven by changes in carbon emissions. When both OE and EE are taken into account, it is found that WaSCs performed better than WoCs. However, the ECOE for both types of companies was decreasing at an annual rate of almost 7\%. Thus, during that period (2016-2018), water companies did not manage to improve their managerial practices leading to higher levels of carbon emissions released in the atmosphere. In particular, in 2018 the potential savings for costs (e.g., energy and other) and carbon emissions among WaSCs and WoCs were $34.6 \%$ and $38.6 \%$, on average. Overall, the results indicated that although WaSCs were more eco-efficient than WoCs during the years 2011-2018, there is still room for improvements in their production process. Methods to reduce production costs and carbon emissions could be for instance the use of more efficient energy techniques when pumping water from different resources and the use of more renewable energy in the treatment process.

Table 3 reports the efficiency scores and the relevant rankings at a company level during the years 2011-2018. Several interesting conclusions can be drawn from these results. First, the number of water companies that were found to be eco-efficient were smaller than the ones from an operational point of view. For instance, five water companies ( $3 \mathrm{WaSCs}$ and $2 \mathrm{WoCs}$ ) were $100 \%$ efficient from a production point of view. However, when GHG emissions were included in the analysis, only two companies ( 2 WaSCs) were $100 \%$ efficient. The other water companies were found to be considerably inefficient in terms of EE and ECOE. This finding evidences that reducing carbon emissions is challenging for most water companies. Moreover, the potential savings in costs from an operational point of view varied between $0 \%$ and $8.9 \%$ among companies. Nevertheless, considerable more savings were possible from an environmental point of view. These savings ranged from $0 \%$ to $23.4 \%$ on average over the whole period of study. There were several WaSCs with lower EE scores than WoCs which means that larger firms might not be more efficient than smaller ones. WaSCs' unified efficiency scores varied from 0.660 to 1.000 suggesting that the worst water company needed to curtail costs and carbon emissions by $34 \%$ while expanding output to catch-up with the most eco-efficient companies in the sample. In contrast, higher cost savings were possible for WoCs as their ECOE scores ranged from 0.650 to 0.842 . Thus, while delivering more water to more customers, average WoCs could reduce production costs and GHG emissions between $15.8 \%$ and $35 \%$.

\subsection{Effect of Environmental Variables on Eco-Efficiency Scores}

In order to comprehend what drives eco-efficiency of the UK water companies, we regressed the ECOE scores against a set of environmental factors. The findings are reported in Table 4. It is found that water taken from rivers and boreholes, advanced levels of water treatment, population density and the number of treatment works from surface water had a statistically important effect on eco-efficiency. Among these variables, advanced water treatment and population density had the major impact on eco-efficiency as indicated by the magnitude of the estimated coefficient. In particular, keeping other factors constant, one unit increase in the level of water treatment complexity, it would decrease eco-efficiency by 0.737 units on average. This result evidences that the more advanced the treatment of water is, the higher the costs of treatment could be. It illustrates the importance of developing and 
implementing policies at watershed level to prevent water pollution and therefore, to avoid the use of advanced treatment to produce drinking water. In contrast, one unit increase in population density could lead to an increase in efficiency by 0.311 units on average. This finding suggests that delivering water to densely populated areas might require lower operating costs and GHG emissions. Moreover, it is found that when more water is abstracted from rivers and wells, it is likely that the use of pumps could be higher. This might result in higher carbon emissions and inefficiency. Finally, the higher the number of works to treat water from surface water resources the lower the costs of treatment could be. However, its impact on efficiency is immaterial as shown by the small magnitude of the estimated coefficient.

Table 3. Average operational efficiency (OE), environmental efficiency (EE) and eco-efficiency (ECOE) and ranking of English and Welsh water companies.

\begin{tabular}{ccccccc}
\hline & \multicolumn{2}{c}{ Operational Efficiency } & \multicolumn{2}{c}{ Environmental Efficiency } & \multicolumn{2}{c}{ Eco-Efficiency } \\
\hline & Score & Rank & Score & Rank & Score & Rank \\
\hline WaSC1 & 0.986 & 7 & 0.766 & 17 & 0.679 & 13 \\
WaSC2 & 0.891 & 17 & 0.831 & 11 & 0.694 & 12 \\
WaSC3 & 1.000 & 1 & 0.844 & 8 & 0.786 & 8 \\
WaSC4 & 0.941 & 15 & 0.863 & 7 & 0.841 & 5 \\
WaSC5 & 0.969 & 11 & 0.782 & 14 & 0.660 & 15 \\
WaSC6 & 0.999 & 6 & 1.000 & 1 & 1.000 & 1 \\
WaSC7 & 1.000 & 1 & 1.000 & 1 & 1.000 & 2 \\
WaSC8 & 1.000 & 1 & 0.982 & 3 & 0.984 & 3 \\
WaSC9 & 0.973 & 10 & 0.766 & 16 & 0.644 & 17 \\
WaSC10 & 0.963 & 13 & 0.807 & 12 & 0.739 & 11 \\
WoC1 & 0.911 & 16 & 0.796 & 13 & 0.675 & 14 \\
WoC2 & 0.963 & 14 & 0.837 & 9 & 0.740 & 10 \\
WoC3 & 1.000 & 1 & 0.872 & 6 & 0.812 & 7 \\
WoC4 & 1.000 & 1 & 0.873 & 5 & 0.825 & 6 \\
WoC5 & 0.979 & 9 & 0.912 & 4 & 0.842 & 4 \\
WoC6 & 0.964 & 12 & 0.774 & 15 & 0.650 & 16 \\
WoC7 & 0.984 & 8 & 0.833 & 10 & 0.746 & 9 \\
\hline
\end{tabular}

Table 4. Estimated results from the regression model to identify drivers of eco-efficiency.

\begin{tabular}{ccccc}
\hline Variables & Coef. & Std. Err. & z-Stat & $p$-Value \\
\hline Constant & 1.331 & 0.282 & $\mathbf{4 . 7 2 0}$ & 0.000 \\
Water abstracted from rivers & -0.084 & 0.043 & $\mathbf{- 1 . 9 4 0}$ & 0.052 \\
Water abstracted from boreholes & -0.058 & 0.034 & $\mathbf{- 1 . 7 2 0}$ & 0.085 \\
Advanced water treatment & -0.737 & 0.286 & $\mathbf{- 2 . 5 8 0}$ & 0.010 \\
Average pumping head & 0.000 & 0.000 & -0.780 & 0.437 \\
Population density & 0.311 & 0.110 & $\mathbf{2 . 8 4 0}$ & 0.005 \\
Number of SW treatment works & 0.008 & 0.002 & $\mathbf{3 . 1 5 0}$ & 0.002 \\
Year & & & & \\
2012 & 0.018 & 0.018 & 1.010 & 0.311 \\
2013 & 0.023 & 0.018 & 1.280 & 0.202 \\
2014 & 0.012 & 0.018 & 0.660 & 0.507 \\
2015 & 0.018 & 0.018 & 1.040 & 0.298 \\
2016 & -0.046 & 0.018 & $-\mathbf{2 . 6 0 0}$ & 0.009 \\
2017 & -0.003 & 0.018 & -0.160 & 0.869 \\
2018 & -0.170 & 0.021 & $-\mathbf{8 . 1 8 0}$ & 0.000 \\
Log-likelihood & 148.480 & & & \\
Wald X ${ }^{2}(13)$ & $\mathbf{2 5 0 . 1 9 0}$ & & & \\
$p$-value & 0.000 & & &
\end{tabular}

Dependent variable = efficiency score; Bold statistics are statistically significant at 5\% significance level; Bold and italic statistics are statistically significant at $10 \%$ significance level. 
The findings of our approach can be of great importance to policy makers. First, our approach gives them the opportunity to evaluate the performance of water companies from three perspectives namely: operational efficiency (OE), environmental efficiency (EE) and eco-efficiency (ECOE). Although water companies might do well in terms of operational efficiency, this might not be the case when GHG are included in the analysis. Actually, the empirical application has showed that if GHG emissions were ignored, water companies reported high levels of OE. However, if GHG emissions are incorporated in the estimation process, then the potential savings in costs and GHG emissions are substantial. This finding suggests that reducing GHG emissions is challenging for the water companies. Thus, policy makers need to be aware of not only their OE but also their ECOE when making decisions on how to operate their assets. Moreover, our analysis showed that there might be several operating characteristics that might impact water companies' eco-efficiency such as water treatment complexity and density. Including these factors in water companies' managerial practices could help them make informed decisions.

\section{Conclusions}

The path towards a sustainable and carbon neutral water cycle requires information on how water companies perform both from a production and environmental point of view. This can be done by assessing the efficiency of the water supply process, the ability of a water company to reduce its costs and carbon emissions while trying to expand its output (drinking water service). In this study, it is employed, for the first time, the non-radial RAM-DEA approach to estimate the OE, EE and ECOE of several water companies in England and Wales. The further use of regression techniques permitted us to determine the effect of several environmental variables on companies' eco-efficiency.

The main points can be summarized as follows. First, it is found that during the years 2011-2018, on average, water companies reported high OE scores, 0.972 . This means that while delivering more water to more customers, companies needed to further reduce energy and other costs by $2.8 \%$. However, when GHG emissions were incorporated in the analysis, efficiency scores obtained lower values. From an environmental point of view, the savings for costs and GHG could reach the level of $14.6 \%$ on average. Moreover, the mean ECE score was 0.783 which means that while expanding water services, companies could further reduce costs and GHG emissions by $11.7 \%$ on average. Thus, the findings indicate that eco-inefficiency exists. Water companies need to considerably improve their managerial practices by adopting new technologies that could allow them to decrease production costs and carbon emissions. Our results also showed that WaSCs were more eco-efficient than WoCs. The potential savings in costs and GHG emissions while delivering more water to customers could be almost $20 \%$ among WaSCs and $25 \%$ among WoCs on average. A downward trend in the WaSCs and WoCs eco-efficiency scores was apparent from 2016 onwards suggesting that reducing carbon emissions during the 2014 price review was challenging. The regulator could interfere by designing policies that could incentivize the water companies to adopt new environmentally technologies such as the use of renewable energy in the water treatment process. Factors that could have a major influence on water companies' eco-efficiency included advanced levels of water treatment, water taken from rivers and boreholes and population density.

The following policy implications can be discussed based on the findings of our study. First, our results demonstrated that regulated water companies need to act to improve their eco-efficiency. This can be achieved by making reductions in both production costs and carbon emissions. Examples might include the use of more energy efficient techniques when pumping water from different water resources or employing pumps more closely adjusted to the required need. Another example could include the use of renewable energy during the treatment of water which could reduce the use of energy and its costs. This could consequently result in lower GHG emissions released to the atmosphere. The water regulator could design and introduce policies that could incentivize water companies to use carbon neutral technologies in the production process. Moreover, our study showed 
that there might be other operating characteristics that could impact water companies' eco-efficiency. For instance, the more advanced the treatment of water is the higher the energy costs and carbon emissions could be. Thus, ensuring that the water abstracted from different water resources is clean should be of great significance. Densely populated areas might require shorter pipes to connect and move water so operating costs and levels of carbon emissions might be lower. These factors should be considered in the business making decision process as they could lead to an eco-efficient water industry. Overall, we believe that our approach could be of great interest to policy makers at they can evaluate the economic and environmental efficiency of the water abstraction, treatment and supply process. Our method can help managers and regulators to make robust comparisons among the water utilities assessed and quantify the savings that could be achieved in terms of operating costs such as energy and other costs, and in terms of greenhouse gas emissions. Moreover, policy makers could identify best and worst performers in the industry and introduce incentives to enhance efficiency such as financial penalties when economic and environmental targets are met. We finally note that policy makers could further get a better insight what drives eco-performance in the water cycle. In particular, the adoption of innovative solutions such as the use of renewable energy to reduce the costs of advanced water treatment could enhance eco-efficiency. We believe that the above topics could enable managers to make the right economic and environmental decisions that could lead to a greener economy and society.

Author Contributions: Conceptualization, A.M. and M.M.-S.; methodology, A.M.; software, M.M.-A. and R.S.-G.; validation, M.M.-S. and M.M.-A.; formal analysis, R.S.-G.; investigation, A.M.; resources, M.M.-A.; data curation, A.M.; writing—original draft preparation, A.M.; writing-review and editing, M.M.-S.; visualization, M.M.-S.; supervision, R.S.-G.; project administration, M.M.-A. and R.S.-G. All authors have read and agreed to the published version of the manuscript.

Funding: This research received no external funding.

Institutional Review Board Statement: Not applicable.

Informed Consent Statement: Not applicable.

Data Availability Statement: Data will be available upon reasonable request.

Conflicts of Interest: The authors declare no conflict of interest.

\section{References}

1. Molinos-Senante, M.; Hernández-Sancho, F.; Sala-Garrido, R. Economic feasibility study for wastewater treatment: A cost-benefit analysis. Sci. Total Environ. 2010, 408, 4396-4402. [CrossRef] [PubMed]

2. Rothausen, S.; Conway, D. Greenhouse-gas emissions from energy use in the water sector. Nat. Clim. Chang. 2011, 1, 210-219. [CrossRef]

3. CIWEM. A Blueprint for Carbon Emissions Reduction in the UK Water Industry; The Chartered Institution of Water and Environmental Management: London, UK, 2013; pp. 1-44.

4. Ananda, J.; Hampf, B. Measuring environmentally sensitive productivity growth: An application to the urban water sector. Ecol. Econ. 2015, 116, 211-219. [CrossRef]

5. Lam, K.L.; Kenway, S.J.; Lant, P.A. Energy use for water provision in cities. J. Clean. Prod. 2017, 143, 699-709. [CrossRef]

6. Lee, M.; Keller, A.A.; Chiang, P.-C.; Den, W.; Wang, H.; Hou, C.-H.; Wu, J.; Wang, X.; Yan, J. Water-energy nexus for urban water systems: A comparative review on energy intensity and environmental impacts in relation to global water risks. Appl. Energy 2017, 205, 589-601. [CrossRef]

7. Wang, X.-C.; Klemes, J.J.; Wang, Y.; Dong, X.; Wei, H.; Xu, Z.; Varbanov, P.S. Water-Energy-Carbon Emissions nexus analysis of China: An environmental input-output model-based approach. Appl. Energy 2020, 261, 114431. [CrossRef]

8. Ananda, J. Productivity implications of the water-energy-emissions nexus: An empirical analysis of the drinking water and wastewater sector. J. Clean. Prod. 2018, 196, 1097-1105. [CrossRef]

9. Engström, R.E.; Howells, M.; Destouni, G.; Bhatt, V.; Bazilian, M.; Rogner, H.-H. Connecting the resource nexus to basic urban service provision-with a focus on water-energy interactions in New York City. Sustain. Cities Soc. 2017, 31, 83-94. [CrossRef]

10. Sala-Garrido, R.; Mocholi-Arce, M.; Molinos-Senante, M.; Maziotis, A. Marginal abatement cost of greenhouse gas emissions in the provision of urban drinking water. Sustain. Prod. Consum. 2021, 25, 439-449. [CrossRef]

11. Worthington, A.C. A review of frontier approaches to efficiency and productivity measurement in urban water utilities. Urban Water J. 2014, 11, 55-73. [CrossRef] 
12. Cetrulo, T.B.; Marques, R.C.; Malheiros, T.F. An analytical review of the efficiency of water and sanitation utilities in developing countries. Water Res. 2019, 161, 372-380. [CrossRef]

13. Goh, K.H.; See, K.F. Twenty Years of Water Utility Benchmarking: A Bibliometric Analysis of Emerging Interest in Water Research and Collaboration. J. Clean. Prod. 2021, 284, 124711. [CrossRef]

14. Chung, Y.H.; Färe, R.; Grosskopf, S. Productivity and undesirable outputs: A directional distance function approach. J. Environ. Manag. 1997, 51, 229-240. [CrossRef]

15. Färe, R.; Grosskopfm, S. Modeling undesirable factors in efficiency evaluation: Comment. Eur. J. Oper. Res. 2004, 157, 242-245. [CrossRef]

16. Ananda, J. Explaining the environmental efficiency of drinking water and wastewater utilities. Sustain. Prod. Consum. 2019, 17, 188-195. [CrossRef]

17. Schaltegger, S.; Sturm, A. Ecological rationality: Approaches to design of ecology-oriented management instruments. Die Unternehm 1990, 4, 273-290.

18. Charnes, A.; Cooper, W.W.; Rhodes, E. Measuring the efficiency of decision making units. Eur. J. Oper. Res. 1978, 2, 429-444. [CrossRef]

19. Suárez-Varela, M.; de los Ángeles García-Valiñas, M.; González-Gómez, F.; Picazo-Tadeo, A.J. Ownership and Performance in Water Services Revisited: Does Private Management Really Outperform Public? Water Resour. Manag. 2017, 31, $2355-2373$. [CrossRef]

20. Sueyoshi, T. DEA-discriminant analysis: Methodological comparison among eight discriminant analysis approaches. Eur. J. Oper. Res. 2006, 169, 247-272. [CrossRef]

21. Banker, R.D.; Charnes, A.; Cooper, W.W. Some models for estimating technical and scale inefficiencies in data envelopment analysis. Manag. Sci. 1984, 30, 1078-1092. [CrossRef]

22. Sueyoshi, T.; Sekitani, K. An occurrence of multiple projections in DEA-based measurement of technical efficiency: Theoretical comparison among DEA models from desirable properties. Eur. J. Oper. Res. 2009, 196, 764-794. [CrossRef]

23. Avkiran, N.K.; Tone, K.; Tsutsui, M. Bridging radial and non-radial measures of efficiency in DEA. Ann. Oper. Res. 2008, 164, 127-138. [CrossRef]

24. Sueyoshi, T.; Yuan, Y.; Goto, M. A literature study for DEA applied to energy and environment. Energy Econ. 2017, 62, 104-124.

25. Zhu, J. Non-radial DEA Models and DEA with Preference. In Quantitative Models for Performance Evaluation and Benchmarking, 3rd ed.; Zhu, J., Ed.; Springer International Publishing: Cham, Switzerland, 2014; pp. 121-140.

26. Charnes, A.; Cooper, W.W.; Golany, B.; Seiford, L.M.; Stutz, J. Foundations of data envelopment analysis for Pareto-Koopmans efficient empirical production functions. J. Econom. 1985, 30, 91-107. [CrossRef]

27. Tone, K. A slack-based measure of efficiency in data envelopment analysis. Eur. J. Oper. Res. 2001, 130, 498-509. [CrossRef]

28. Cooper, W.W.; Park, K.S.; Pastor, J.T. RAM: A range adjusted measure of inefficiency for use with additive models and relations to other models and measures in DEA. J. Product. Anal. 1999, 11, 5-42. [CrossRef]

29. Cooper, W.W.; Park, K.S.; Pastor, J.T. Marginal rates and elasticities of substitution with additive models in DEA. J. Product. Anal. 2000, 13, 105-123. [CrossRef]

30. Cooper, W.W.; Park, K.S.; Pastor, J.T. The range adjusted measure (RAM) in DEA: A response to the comment by Steinmann and Zweifel. J. Product. Anal. 2001, 15, 145-152. [CrossRef]

31. Pastor, J.T.; Ruiz, J.L.; Sirvent, I. An enhanced DEA Russell graph efficiency measure. Eur. J. Oper. Res. 1999, 115, 596-607. [CrossRef]

32. Sueyoshi, T.; Goto, M. Should the US clean air act include $\mathrm{CO}_{2}$ emission control? Examination by data envelopment analysis. Energy Policy 2010, 38, 5902-5911. [CrossRef]

33. Sueyoshi, T.; Goto, M. DEA approach for unified efficiency measurement Assessment of Japanese fossil fuel power generation. Energy Econ. 2011, 33, 292-303. [CrossRef]

34. Sueyoshi, T.; Goto, M. Measurement of Returns to Scale and Damages to Scale for DEA-based operational and environmental assessment: How to manage desirable (good) and undesirable (bad) outputs? Eur. J. Oper. Res. 2011, 211, 76-89. [CrossRef]

35. Sueyoshi, T.; Goto, M. Methodological comparison between two unified (operational and environmental) efficiency measurements for environmental assessment. Eur. J. Oper. Res. 2011, 210, 684-693. [CrossRef]

36. Sueyoshi, T.; Goto, M. Data envelopment analysis for environmental assessment: Comparison between public and private ownership in petroleum industry. Eur. J. Oper. Res. 2012, 216, 668-678. [CrossRef]

37. Wang, K.; Lu, B.; Wei, Y.-M. China's regional energy and environmental efficiency: A Range-Adjusted Measure based analysis. Appl. Energy 2013, 112, 1403-1415. [CrossRef]

38. Sueyoshi, T.; Goto, M. DEA environmental assessment in time horizon: Radial approach for Malmquist index measurement on petroleum companies. Energy Econ. 2015, 51, 329-345. [CrossRef]

39. Sueyoshi, T.; Goto, M. Environmental assessment on coal-fired power plants in U.S. north-east region by DEA non-radial measurement. Energy Econ. 2015, 50, 125-139. [CrossRef]

40. Sueyoshi, T.; Goto, M.; Ueno, T. Performance analysis of US coal-fired power plants by measuring three DEA efficiencies. Energy Policy 2010, 38, 1675-1688. [CrossRef]

41. Sala-Garrido, R.; Mocholi-Arce, M.; Molinos-Senante, M.; Smyrnakis, M.; Maziotis, A. Eco-Efficiency of the English and Welsh Water Companies: A Cross Performance Assessment. Int. J. Environ. Res. Public Health 2021, 18, 2831. [CrossRef] 
42. Hoff, A. Second stage DEA: Comparison of approaches for modelling the DEA score. Eur. J. Oper. Res. 2007, 181, 425-435. [CrossRef]

43. Byrnes, J.; Crase, L.; Dollery, B.; Villano, R. The relative economic efficiency of urban water utilities in regional New South Wales and Victoria. Resour. Energy Econ. 2010, 32, 439-455. [CrossRef]

44. Luo, J.H.; Cui, Y.Y.; Ji, J.H. Analysis on container ports efficiency and its influencing factors on two stage method of DEA-TOBIT. Sci. Technol. Manag. Res. 2013, 33, 236-239.

45. Ding, Z.Y.; Jo, G.S.; Wang, Y.; Yeo, G.T. The relative efficiency of container terminals in small and medium-sized ports in China. Asian J. Shipp. Logist. 2015, 31, 231-251. [CrossRef]

46. Guerrini, A.; Romano, G.; Leardini, C.; Martini, M. The Effects of Operational and Environmental Variables on Efficiency of Danish Water and Wastewater Utilities. Water 2015, 7, 3263-3282. [CrossRef]

47. Zhang, J.; Fang, H.; Peng, B.; Wang, X.; Fang, S. Productivity Growth-Accounting for Undesirable Outputs and Its Influencing Factors: The Case of China. Sustainability 2016, 8, 1116. [CrossRef]

48. Wang, X.; Han, L.; Yin, L. Environmental Efficiency and Its Determinants for Manufacturing in China. Sustainability 2017, 9 , 47. [CrossRef]

49. Wang, L.; Zhou, Z.; Yang, Y.; Wu, J. Green efficiency evaluation and improvement of Chinese ports: A cross-efficiency model. Transp. Res. Part D 2020, 88, 102590. [CrossRef]

50. Molinos-Senante, M.; Porcher, S.; Maziotis, A. Impact of Regulation on English and Welsh Water-Only Companies: An Input Distance Function Approach. Environ. Sci. Pollut. Res. 2017, 24, 16994-17005. [CrossRef] [PubMed]

51. Berg, S.; Marques, R.C. Quantitative studies of water and sanitation utilities: A benchmarking literature survey. Water Policy 2011, 13, 591-606. [CrossRef]

52. Carvalho, P.; Marques, R.C.; Berg, S. A meta-regression analysis of benchmarking studies on water utilities market structure. Util. Policy 2012, 21, 40-49. [CrossRef]

53. Pinto, F.S.; Simoes, P.; Marques, R.C. Water services performance: Do operational environmental and quality factors account? Urban Water J. 2017, 14, 773-781. [CrossRef]

54. Stone \& Webster Consultants. Investigation into Evidence for Economies of Scale in the Water and Sewerage Industry in England and Wales: Final Report; Ofwat: London, UK, 2004; pp. 1-62.

55. Portela, M.C.A.S.; Thanassoulis, E.; Horncastle, A.; Maugg, T. Productivity change in the water industry in England and Wales: Application of the Meta-Malmquist index. J. Oper. Res. Soc. 2011, 62, 2173-2188. [CrossRef]

56. Molinos-Senante, M.; Maziotis, A.; Sala-Garrido, R. The Luenberger productivity indicator in the water industry: An empirical analysis for England and Wales. Util. Policy 2014, 30, 18-28. [CrossRef]

57. Mocholi-Arce, M.; Sala-Garrido, R.; Molinos-Senante, M.; Maziotis, A. Performance assessment of water companies: A metafrontier approach Accounting for quality of service and group heterogeneities. Socio Econ. Plan. Sci. 2021, 74, 100948. [CrossRef]

58. Walker, N.L.; Styles, D.; Gallagher, J.; Williams, A.P. Aligning efficiency benchmarking with sustainable outcomes in the United Kingdom water sector. J. Environ. Manag. 2021, 287, 112317.

59. Saal, D.S.; Parker, D.; Weyman-Jones, T. Determining the contribution of technical efficiency. and scale change to productivity growth in the privatized English and Welsh water and sewerage industry: 1985-2000. J. Product. Anal. 2007, 28, 127-139. [CrossRef]

60. Brea-Solis, H.; Perelman, S.; Saal, D.S. Regulatory incentives to water losses reduction: The case of England and Wales. J. Product. Anal. 2017, 47, 259-276. [CrossRef]

61. Ofwat. Preparing for the Future-Ofwat's Climate Change Policy Statement; The Water Services Regulation Authority: Birmingham, UK, 2010; pp. 1-6.

62. Ofwat. Playing Our Part-Reducing Greenhouse Gas Emissions in the Water and Sewerage Sectors Supporting Information; The Water Services Regulation Authority: Birmingham, UK, 2010; pp. 1-43.

63. Molinos-Senante, M.; Hanley, N.; Sala-Garrido, R. Measuring the $\mathrm{CO}_{2}$ shadow price for wastewater treatment: A directional distance function approach. Appl. Energy 2015, 144, 241-249. [CrossRef]

64. Molinos-Senante, M.; Guzman, C. Reducing $\mathrm{CO}_{2}$ emissions from drinking water treatment plants: A shadow price approach. Appl. Energy 2018, 210, 623-631. [CrossRef]

65. HM Government. Environmental Reporting Guidelines: Including Streamlined Energy and Carbon Reporting Guidance March 2019 (Updated Introduction and Chapters 1 and 2); HM Government: London, UK, 2019; pp. 1-152.

66. Ofwat. Cost Assessment for PR19: A Consultation on Econometric Cost Modelling; The Water Services Regulation Authority: Birmingham, UK, 2018; pp. 1-29.

67. Ofwat. PR19 Final Determinations: Securing Cost Efficiency Technical Appendix; The Water Services Regulation Authority: Birmingham, UK, 2019; pp. 1-222.

68. Ofwat. PR19 Final Determinations: Supplementary Technical Appendix: Econometric Approach; The Water Services Regulation Authority: Birmingham, UK, 2019; pp. 1-42.

69. Molinos-Senante, M.; Maziotis, A. Drivers of productivity change in water companies: An empirical approach for England and Wales. Int. J. Water Resour. Dev. 2020, 36, 972-991. [CrossRef]

70. Villegas, A.; Molinos-Senante, M.; Maziotis, A. Impact of environmental variables on the efficiency of water companies in England and Wales: A double-bootstrap approach. Environ. Sci. Pollut. Res. 2019, 26, 31014-31025. [CrossRef] [PubMed] 
71. Walker, N.L.; Norton, A.; Harris, I.; Williams, A.P.; Styles, D. Economic and environmental efficiency of UK and Ireland water companies: Influence of exogenous factors and rurality. J. Environ. Manag. 2019, 241, 363-373. [CrossRef] [PubMed]

72. Walker, N.L.; Williams, A.P.; Styles, D. Key performance indicators to explain energy \& economic efficiency across water utilities, and identifying suitable proxies. J. Environ. Manag. 2020, 269, 110810.

73. Molinos-Senante, M.; Maziotis, A. Assessing the influence of exogenous and quality of service variables on water companies performance using a true-fixed stochastic frontier approach. Urban Water J. 2018, 15, 682-691. [CrossRef]

74. Sala-Garrido, R.; Mocholi-Arce, M.; Molinos-Senante, M.; Maziotis, M. Assessing the marginal cost of reducing greenhouse gas emissions in the English and Welsh water and sewerage industry: A parametric approach. Util. Policy 2021, 70, 101193. [CrossRef] 